\title{
The Effect of Counseling With Cognitive Behavioral Approach (CBT) on Self-esteem and Body Image of Lactating Mothers: Randomized Control Trial
}

\section{Nasrin Zamiri-Miandoab}

Tabriz University of Medical Sciences

\author{
Mojgan Mirghafourvand \\ Tabriz University of Medical Sciences
}

Fatemeh Nemati

University of Tabriz

Mahin Kamalifard ( $\nabla$ kamalifardm@tbzmed.ac.ir)

Tabriz University of Medical Sciences https://orcid.org/0000-0002-6455-4809

\section{Research}

Keywords: self-esteem, body image, exclusive breastfeeding, cognitive behavior therapy, lactating mothers

Posted Date: May 17th, 2021

DOl: https://doi.org/10.21203/rs.3.rs-509473/v1

License: (9) (1) This work is licensed under a Creative Commons Attribution 4.0 International License. Read Full License 


\section{Abstract}

Background:Self-esteem and body image are the factors that change during different periods of a woman's life. Some of the women experience low self-esteem and negative body image in Pregnancy and postpartum. These two factors along with other factors can reduce the rate of exclusive breastfeeding among women. Cognitive-behavior therapy is one of the psychological approaches that is effective on the betterment of many of the psychological and personality disorders such as body image disorder as well as improvement of self-esteem.

The aim of this randomized control trial is to recognize the effects of cognitive-behavior counseling during pregnancy period on self-esteem, body image (primary outcome) and exclusive breastfeeding (secondary outcome).

Methods: In this randomized controlled trial, 70 eligible pregnant women referring to health centers of Tabriz-Iran were assigned to two groups of 35 as intervention and control groups using randomized blocking method. For intervention group, 8 sessions of cognitive-behavior therapy based on Cash and Strachan's therapeutic protocol for body image and Michael Free's for self-esteem were performed. Rosenberg self-esteem scale and multidimensional body self-relation questionnaire (MBSRQ) were completed before intervention, immediately after intervention, and 4 weeks after delivery. Likewise, exclusive breastfeeding questionnaire was completed 4 weeks after childbirth. Independent t-test, chi square and repeated measures ANOVA tests were used to analyze the data.

Results: According to repeated measures ANOVA test and with controlling baseline score, the mean scores on self-esteem (adjusted mean difference (AMD): 7.18; 95\% Cl: 4.43 to 9.94; $p<0.001$ ) and body image (AMD: $49.74 ; 95 \% \mathrm{Cl}: 70.91$ to $28.54 ; \mathrm{p}<0.001$ ) in the intervention group were significantly higher than the control group. $63.6 \%$ of intervention group mothers and $30.3 \%$ of control group mothers had exclusive breastfeeding which for the intervention group was significantly higher than the control group based on chi square test $(p=0.007)$.

Conclusions: Cognitive-behavior approach was effective on the improvement of self-esteem and body image and through which might lead to the increase of exclusive breastfeeding among women.

Trial register number. Iranian registry clinical trials (IRCT20110524006582N33). Date of registration: 2020-8-19. URL: https://en.irct.ir/trial/43395.

\section{Background}

Self-esteem, also called self-respect, is a psychological term which is defined as a positive or negative attitude toward yourself $[1,2]$. Rosenberg believes that a person with high self-esteem knows himself/herself as a valuable person and respects himself/herself [3]. Self-esteem is so important that occupies a distinct category in Maslow's pyramid in itself [4]. Lack of self-esteem brings about a lot of problems in people's social relationships [5]. Also, it leads to feelings of loneliness and guilt, sexual 
dysfunction, eating disorders [6], anxiety [7], and depression [8]. Self-esteem is subject to change during different periods of life [7]. Pregnancy is one of the periods in which women experience low self-esteem due to physiological, anatomical, and psychological changes they undergo [9]. Lack of self-esteem is accompanied with poor mental and physical health of mothers and affects infants' health as well as mother-infant attachment negatively $[10,11]$.

Many factors affect the formation of self-esteem like genetics, age, socio economic status, thought patterns [12], health conditions, parents, childhood events, and ...[7]. Likewise, social norms regarding body, especially family member's and friend's ideas as well as deficiencies in appearance can affect selfesteem greatly $[13,14]$. Body image is one of the other essential and influential factors on self-esteem. Some studies show that low self-esteem leads to poor body image while other studies indicate that dissatisfaction with body image leads to low self-esteem [15].

Body image refers to the person's beliefs and feelings about his/her physical appearance (such as height, weight, and body shape) and his/her body sexual attractiveness on the basis of society standards [16]. Although body image is an inner feeling, external factors like friends, family members, social environment and media play essential roles in shaping a person's perception and feelings about his/her appearance [17]. Studies show that body image dissatisfaction among Iranian women has grown conspicuously in recent years [18]. Body image, like self-esteem, is subject to change during a woman's different periods of life, including menstruation, pregnancy [19,20], breastfeeding and postpartum [21]. The poor body image leads to the feelings of unattractiveness and dissatisfaction with marital relations [22], depression [23], eating disorders [24], and low self-esteem [25]. Postpartum depression rate is higher among women with poor body image [26]. Likewise, mothers who were dissatisfied with their body image after delivery had a more negative attitude toward breastfeeding [27].

Self-esteem [28] and body image [29] are among important and influential factors determining exclusive breastfeeding. Nowadays, just $40 \%$ of infants receive exclusive breastfeeding throughout the world. This occurs despite the fact that, according to UNICEF, if exclusive breastfeeding increases, more than 80,000 infants under 5 will rescue from death [30]. This is observed that when women are self-confident and properly supported by family members and others, they will experience a positive and long-term breastfeeding [31]. According to World Health Organization (WHO), counseling as well as supportive and promotional programs are required for starting and continuing breastfeeding [32].

Counseling is a process that helps the betterment of a person's attitude, behavior, and personality. Moreover, counseling leads to the improvement of communication skills, behavior change, mental health, and self-esteem empowering [33]. CBT is a counseling approach that is used exclusively or in combination with other approaches to treat personality disorders, mental disorders, depression, anxiety, and impaired body image [34]. In this approach, the therapist does not question the client's feelings, but challenges the thoughts that bring about such feelings and explains to the clients about the process through which their thoughts lead to their feelings [35]. This approach teaches mothers to avoid prejudgment and negative assessment and demonstrate suitable emotional responses in life stressful 
situations including pregnancy, breastfeeding and postpartum periods [28]. Considering low self-esteem and impaired body image of some women and the impact of these two factors on exclusive breastfeeding, we decided to study the effects of pregnancy counseling based on cognitive-behavior approach on self-esteem, body image (primary outcomes) and exclusive breastfeeding (secondary outcome).

\section{Methods}

\section{Study design and participants}

This randomized controlled trial was performed on 70 pregnant women referred to Tabriz health centers in 2020. The inclusion criteria for this study were minimum secondary school, gestational age of 25-28 weeks, first or second delivery, being singleton, lack of diseases affecting pregnancy process, not using drugs affecting mental-psychological problems, and no history of intense depression. Women with a history of bleeding during the second stage of pregnancy and also a history of malignant breast diseases were not included in the study.

\section{Sampling}

After receiving the approval of the ethics committee and registering the study in the Iranian Registry of Clinical Trials with code IRCT20110524006582N33, the sampling permission was received from the research deputy of nursing-midwifery school and the deputy of health department of East Azerbaijan province in Iran. The researcher referred to the health centers of populous and socio-culturally different districts of Tabriz and extracted the list of pregnant women from the files. Then, these women were contacted via phone number, and goals and methods of research were explained for them briefly on the phone. Moreover, they were analyzed based on inclusion and exclusion criteria and if they were eligible and willing to participate in the study, they were invited to be present in relevant centers at specified times. In this face to face meeting, the goals and methods of research were explained thoroughly and if the pregnant mother was willing to participate in the study, written informed consent was obtained from her and Rosenberg self-esteem scale and Multidimensional Body-Self Relations Questionnaire (MBSRQ) were completed by participants. Women who scored lower than 241 based on Multidimensional BodySelf Relations Questionnaire (MBSRQ) [36] and lower than 25 based on Rosenberg self-esteem scale [3739] were included in the study. Then, a socio-demographic questionnaire was completed by participants.

\section{Random allocation and intervention}

Participants were assigned to two intervention and control groups (35 people in each group) using random blocking method stratified on the basis of the first or second delivery with 4 to 6 people in each block. For allocation concealment, the type of intervention was written on papers by a person uninvolved in the study and put in opaque envelops that were numbered sequentially.

For intervention group, counseling based on cognitive-behavior approach was performed in 8 sessions of 60 to 90 minutes once a week by a master student of counseling in midwifery that was trained for CBT by 
a professional psychologist. The sessions were held in a room in health centers considered for counseling in a calm environment. Counseling for body image was based on Cash and Strachan's body image workbook [40] and for self-esteem was based on Michael Free's Cognitive Therapy in Groups:

Guidelines and Resources for Practice [41]. The contents of sessions are presented in the Table 1. Due to pandemic Covid-19 and the necessity of observing social distance, the number of participants was between at least 3 and at most 5 people in each session (depending on the available space in the health centers). 


\section{Sessions Contents of each session}

Session Participants' introducing and getting familiar with each other and establishing the first
contact, presenting the goals and rules of the group and the important issue of
confidentiality, introducing methods and processes of treatment, explanation about and
agreement on participatory nature of the sessions and necessity of doing homework,
explanation and discussion about the meanings of self-esteem and body image and
related factors

Session Reviewing contents of the previous session, indicating the effects of cultural, social, and 2 psychological pressures as well as life experiences and biography on self-esteem and body image, stating factors lowering or improving self-esteem, awareness of interactional nature of three systems, i.e. thinking, behavioral, and physiological systems, familiarity with Albert Ellis' A-B-C model, practicing self-monitoring skills and presenting homework

Session3 Reviewing contents of previous sessions, checking homework, recognizing negative selftalks about body image and low self-esteem, practicing and improving positive self-talks about body image and self-worth, teaching deep breathing technique, teaching relaxation and practicing group relaxation with the participation of all members of the group, presenting homework

Session4 Reviewing contents of previous sessions, checking homework, analyzing the role of beliefs on body image and self-esteem, taking actions to inhibit maladaptive and negative thoughts and feelings through recognition of self-humiliating beliefs and replacing them with positive and adaptive thoughts, analyzing and challenging general fundamental misconceptions related to appearance and providing logical responses to them, practicing relaxation, presenting homework

Session Reviewing contents of previous sessions, checking homework, reviewing vertical arrow, 5 familiarity with advanced vertical arrow and types of beliefs, presenting homework

Session Reviewing homework of previous sessions, discussing self-humiliating behaviors 6 concerning body image and self-esteem, training techniques for changing troublesome behavior patterns, practicing relaxation, presenting homework

Session Reviewing homework of previous sessions, giving the body its rights and having a good $7 \quad$ time, training pregnant women for having pleasant times with their bodies and improving their relationships with their bodies through creative involvement and specific exercises for enjoying and admiring their physical beings, training pregnant women for facing their probable physical defects, practicing relaxation as homework

Session Reviewing homework and contents of previous sessions, presenting and reviewing 8 techniques for protecting positive body image and self-esteem, reviewing taught strategies for changing negative beliefs, practicing relaxation, getting feedback about the program from participants and providing an opportunity to finish the group therapy program

\section{Data instruments}

The measures used in this study included socio-demographic and obstetrics questionnaires, Rosenberg self-esteem scale, and Multidimensional Body-Self Relations Questionnaire and exclusive breastfeeding 
questionnaire. Socio-demographic and obstetric questionnaires were completed before the study, and Rosenberg self-esteem scale and Multidimensional Body-Self Relations Questionnaire were completed before intervention, immediately after the completion of the sessions of intervention, and then 4 weeks after childbirth by both of the groups. Likewise, breastfeeding questionnaire was completed via interview one month after childbirth.

\section{Socio-demographic and obstetrics questionnaire}

This questionnaire that was designed by the research team included questions about the participant's and her spouse's age, duration of their marriage, the participant's and her spouse's educational level and occupation, adequacy of income, marital satisfaction, extent of spouse and family support, gestational age and sex of fetus, history of pregnancy, childbirth and abortion, successful breastfeeding history, and .... The validity of the questionnaire was confirmed through face and content validity.

\section{Rosenberg self-esteem questionnaire}

Self-esteem was assessed by Rosenberg self-esteem scale (10 items). This questionnaire contains 10 phrases, 5 first of which are designed as positive and the second 5 as negative. The questionnaire has reverse scoring. The range of scores of this scale is from 0 to 30 . Scores higher than 25 represent high self-esteem and scores between 15 and 25 indicate average self-esteem. Scores lower than 15 signify low self-esteem. In Makikangas study conducted in Finland, Cronbach's alpha coefficients for this scale were calculated 0.87 for men and 0.86 for women in the first turn and 0.88 for men and 0.87 for women in the second turn [29]. Cronbach's alpha coefficient was reported as 0.84 for the Iranian sample [42]. Also, Cronbach's alpha coefficient was calculated 0.86 for the present study.

\section{Multidimensional body self-relations questionnaire}

MBSRQ was developed by Cash et al. in 1990 and its reliability was also confirmed. This questionnaire as a multidimensional measure of attitude toward body image contains cognitive, emotional, and behavioral components and its validity is reported as 0.81 . Subscales of this questionnaire include: appearance evaluation, appearance orientation, fitness evaluation, fitness orientation, health evaluation, health orientation, illness orientation, body area satisfaction (BASS), self-classified weight, overweight preoccupation. This questionnaire has reverse scoring. Questions $6,15,16,17,23,25,28,32,33,34,37$, $38,40,42,43,45,47,48$ and 49 are scored reversely. The minimum total score of a person is 69 and the maximum total score is 395. Higher scores indicate greater physical satisfaction [30]. In a study, Rahati analyzed validity and reliability of this questionnaire for Iranian samples and reported its Cronbach's alpha as 0.88 [32]. Cronbach's alpha of the present study is calculated 0.89 .

\section{Exclusive breastfeeding questionnaire}

This questionnaire was designed by the research team and included questions about exclusive breastfeeding. The validity of this questionnaire was confirmed through face and content validity.

\section{Sample size}


Sample size was calculated using G-power software and on the basis of both variables of self-esteem and body image. Based on a study conducted by Inanir et al. [43] and considering $m_{1}=118.3$ (mean score of body image) and with the assumption of $25 \%$ increase in mean score due to intervention $\mathrm{m}_{2}=$ 147.875 , and power $=95 \%$, sample size of 32 people was calculated for each group which by considering $20 \%$ sample attrition, final sample size would be 35 people in each group. According to a study conducted by Barez et al. [33] and by considering $\mathrm{m}_{1}=28.98$ (mean score of self-esteem) and with the assumption of $25 \%$ increase in mean score due to intervention $\mathrm{m}_{2}=34.776$, and power $=95 \%$, sample size was calculated 8 people in each group which by considering the fact that sample size based on body image score was greater, 35 people in each group was selected as the final sample size.

\section{Data analysis}

After collecting data from all research units, the collected data were analyzed by SPSS-Version24 software. Normality of quantitative data was confirmed by K-S test. To analyze homogeneity of groups in terms of socio-demographic characteristics, Chi-square, Chi-square for trend, independent-t, and Fisher's exact tests were used. To compare mean scores on self-esteem and body image and also subscales of body image among the groups, t-test was used before intervention; and repeated measures ANOVA with controlling the baseline score and variables of participants' and their spouses' educational level, participants' age, and intervals between deliveries was used after intervention. To compare the frequency of exclusive breastfeeding among the groups, Chi-square test was used. All of the tests were performed in terms of intention- to-treat.

\section{Results}

The study started in February 2020, but was quitted for 3 months because of pandemic Covid-19, it was resumed in May 2020 again and was finished in January 2021. In this study, 2 people from the control group (one because of preeclampsia and the other one because of being unavailable) and 2 people from the intervention group (because of pandemic Covid-19 and reluctance to attend the sessions regularly) were excluded from the study. Finally, 33 people in each group were analyzed.

The mean (SD: standard deviation) of participants' and their spouses' ages were 30.51 (4.99) and 35.69 (5.02) years respectively in the intervention group and 27.89 (5.36) and 33.69 (5.86) years respectively in the control group. The mean (SD) of gestational age was 26.86 (1.33) weeks in the intervention group and 26.91(1.34) weeks in the control group. More than half of the participants in the intervention group $(60 \%)$ and less than half of the participants in the control group $(45.7 \%)$ had a university education $(p=$ 0.013). Two thirds of the spouses $(65.7 \%)$ in the intervention group had a university education and less than half of the spouses $(42.9 \%)$ in the control group had diploma $(p=0.026)$. Most of the mothers in both groups were housekeepers ( $82.9 \%$ in the intervention group and $91.4 \%$ in the control group) $(p=$ 0.259). In both groups, most of the spouses were self-employed (57.1\% in the intervention group and $65.7 \%$ in the control group) $(p=0.458)$. About two thirds of the mothers in both groups reported their incomes as almost adequate $(65.7 \%$ in the intervention group and $60 \%$ in the control group) $(p=1.000)$. 
Almost half of the participants in both groups ( $48.6 \%$ in the intervention group and $54.3 \%$ in the control group) were completely satisfied with their marital life $(p=0.941)$. The extent of spouses' support was very good for less than half the participants in both groups (40\% in the intervention and $42.9 \%$ in the control group) $(p=0.259)$. Almost half of the participants in both groups reported the extent of their families' support as very good (45.7\% in the intervention group and $42.9 \%$ in the control group) ( $p=$ $0.821)$. Most of the participants had got pregnant on a planned basis $(71.4 \%$ in the intervention group and $85.7 \%$ in the control group) ( $p=0145)$. In the intervention group, more than half of the fetuses were girls $(54.3 \%)$, but in the control group, more than half of the fetuses were boys $(51.4 \%)(p=0.632)$. Most of the mothers in both groups $(91.4 \%)$ were satisfied with the sex of their fetuses $(p=1.000)$. More than half of the women in both groups (51.4\% in the intervention group and $54.3 \%$ in the control group) had no history of previous delivery $(p=0.811)$. Most of the participants in both groups $(77.1 \%$ in the intervention group and $80 \%$ in the control group) had no history of abortion ( $p=0.771)$. Most of the mothers in the intervention group (70.6\%) and more than half of the mothers in the control group (57.1\%) had no successful history of breastfeeding $(p=0.245)$. On average, length of previous breastfeeding in the intervention group was 17.57 (9.03) months and in the control group $23.20(5.18)$ months $(p=0.055)$. Most of the participants in both groups had a Cesarean delivery $(72.7 \%$ in the intervention group and $84.8 \%$ in the control group). The mean (standard deviation) of participants' BMI before pregnancy was 25.48 (4.20) in the intervention group and 24.26 (4.57) in the control group ( $p=0.260)$. BMI was calculated $28.43(4.43)$ and $26.88(3.86)(p=0.304)$ in the intervention group and $27.27(4.72)$ and $25.81(4.67)(p=0.321)$ in the control group before and after intervention, respectively (Table 2$)$

Table 2. socio-demographic and obstetric characteristic among participants 


\begin{tabular}{|c|c|c|c|c|c|c|c|}
\hline variable & \begin{tabular}{|l|} 
Intervention \\
group(n=35) \\
Number \\
(percent) \\
\end{tabular} & \begin{tabular}{|l} 
Control \\
group(n=35) \\
Number \\
(percent) \\
\end{tabular} & \begin{tabular}{|l}
$\mathrm{p}-$ \\
value
\end{tabular} & variable & \begin{tabular}{|l|} 
Intervention group \\
$(\mathrm{n}=35)$ \\
Number(percent)
\end{tabular} & \begin{tabular}{|l|}
$\begin{array}{l}\text { Control group } \\
(\mathrm{n}=\mathbf{3 5})\end{array}$ \\
Number \\
(percent)
\end{tabular} & $\begin{array}{l}\mathbf{p}- \\
\text { value }\end{array}$ \\
\hline Age (years)* & $30.51(4.99)$ & $27.89(5.36)$ & 0.037 & \multicolumn{3}{|l|}{ Husband's education } & 0.026 \\
\hline $\begin{array}{l}\text { Husband's age } \\
\text { (years)* }\end{array}$ & $35.69(5.02)$ & $33.69(5.86)$ & 0.130 & Mid school & $0(0)$ & $3(8.6)$ & \\
\hline Mother's education & & & 0.013 & High school & $1(2.9)$ & $1(2.9)$ & \\
\hline Mid school & $0(0)$ & $5(14.3)$ & & Diploma & $11(31.4)$ & $16(45.7)$ & \\
\hline high school & $0(0)$ & $3(8.6)$ & & University & $23(65.7)$ & $15(42.9)$ & \\
\hline Diploma & $14(40)$ & $11(31.4)$ & & \multicolumn{3}{|l|}{ Husband's job } & 0.458 \\
\hline University & $21(60)$ & $16(45.7)$ & & No job & $0(0)$ & $1(2.9)$ & \\
\hline Mother's job & & & 0.259 & Employee & $15(42.9)$ & $11(31.4)$ & \\
\hline House work & $29(82.9)$ & $32(91.4)$ & & Self-employee & $20(57.1)$ & $23(65.7)$ & \\
\hline Employee & $6(17.1)$ & $2(5.7)$ & & \multicolumn{3}{|l|}{ Family support } & 0.821 \\
\hline Self-employee & $0(0)$ & $1(2.9)$ & & Very good & $16(45.7)$ & $15(42.9)$ & \\
\hline Family income & & & 1.000 & Good & $16(45.7)$ & $16(45.7)$ & \\
\hline Sufficient & $12(34.3)$ & $10(28.6)$ & & Nearly good & $2(5.7)$ & $4(11.4)$ & \\
\hline Insufficient & $0(0)$ & $4(11.4)$ & & Not good & $1(2.9)$ & $0(0)$ & \\
\hline Nearly sufficient & $23(65.7)$ & $21(60)$ & & \multicolumn{3}{|l|}{ Husband's support } & 0.259 \\
\hline Life satisfaction & & & \begin{tabular}{|l|l|}
0.941 \\
\end{tabular} & Very good & $14(40)$ & $15(42.9)$ & \\
\hline Completely satisfied & $17(48.6)$ & $19(54.3)$ & & Good & $11(31.4)$ & $14(40)$ & \\
\hline Un satisfied & $4(11.4)$ & $4(11.4)$ & & Nearly good & $6(17.1)$ & $6(17.1)$ & \\
\hline Relatively satisfied & $14(40)$ & 12 934.3) & & Not good & $4(11.4)$ & $0(0)$ & \\
\hline History of delivery & & & 0.811 & \multicolumn{3}{|l|}{ Planned pregnancy } & 0.145 \\
\hline Yes & $17(48.6)$ & $16(45.7)$ & & Yes & $25(71.4)$ & $30(85.7)$ & \\
\hline No & $18(51.4)$ & $19(54.3)$ & & No & $10(28.6)$ & $5(14.3)$ & \\
\hline History of abortion & & & 0.771 & \multicolumn{3}{|l|}{ fetal sex } & 0.632 \\
\hline Yes & $8(22.9)$ & $7(20)$ & & Female & $19(54.3)$ & $17(48.6)$ & \\
\hline No & $27(77.1)$ & $28(80)$ & & male & $16(45.7)$ & $18(51.4)$ & \\
\hline History of successful & eastfeeding & & 0.245 & \multicolumn{3}{|l|}{ Wanted fetal sex } & 1.000 \\
\hline Yes & $10(29.4)$ & $15(42.9)$ & & Yes & $32(91.4)$ & $32(91.4)$ & \\
\hline No & $24(70.6)$ & $20(57.1$ & & No & $3(8.6)$ & $3(8.6)$ & \\
\hline $\begin{array}{l}\text { Gestational age } \\
\text { *(week) }\end{array}$ & $26.91(1.33)$ & $26.85(1.33)$ & & \begin{tabular}{|l} 
Marriage \\
duration* (years)
\end{tabular} & $6.57(4.23)$ & $5.34(3.42)$ & \\
\hline $\begin{array}{l}\text { Distance between } \\
\text { deliveries * (years) }\end{array}$ & $8.81(2.42)$ & $5.68(2.98)$ & 0.003 & $\begin{array}{l}\text { Previous B.F }{ }^{\dagger} \\
\text { duration* }\end{array}$ & $17.57(9.03)$ & $23.20(5.18)$ & \\
\hline \multicolumn{3}{|c|}{ History of successful B.F ${ }^{\dagger}$} & 0.245 & \multicolumn{3}{|l|}{ Type of delivery } & 0.228 \\
\hline Yes & $10(29.4)$ & $15(42.9)$ & & NVD & $9(27.3)$ & $5(15.2)$ & \\
\hline No & $24(70.6)$ & $20(57.1)$ & & $\mathrm{CS}$ & $24(72.7)$ & $28(84.8)$ & \\
\hline \multicolumn{3}{|l|}{ Exclusive B.F ${ }^{\dagger}$} & 0.007 & $\begin{array}{l}\text { BMI } \ddagger \text { before } \\
\text { pregnancy }\end{array}$ & $25.48(4.20)$ & $24.26(4.57)$ & \\
\hline Yes & $21(63.6)$ & $10(30.3)$ & & $\begin{array}{l}\text { before } \\
\text { intervention } \mathrm{BMI}_{\ddagger}^{+}\end{array}$ & $28.43(4.43)$ & $27.27(4.43)$ & \\
\hline No & $12(36.4)$ & $23(69.7)$ & & $\begin{array}{l}\text { after intervention } \\
\text { BMI }\end{array}$ & $26.88(3.86)$ & $25.81(4.67)$ & \\
\hline
\end{tabular}

*these scores indicate the mean (SD)

The number of participants before intervention was 70 and after intervention was 66

†B.F: Breastfeeding ‡BMI: body mass index

The mean (SD) of self-esteem, before the onset of counseling, was 15.63 (3.18) in the intervention group, while it was 17.83 (3.40) for the control group ( $p=0.007)$. Immediately after the intervention, self-esteem 
score improved to 23.36 (2.34) in the intervention group and 18.40 (2.06) in the control group. 4 weeks after childbirth, mean self-esteem score was 24.36 (2.50) in the intervention group and 17.13 (3.40) in the control group. Before the intervention, there was significant statistical difference between two groups based on independent t-test $(p=0.007)$. Likewise, after the intervention, mean self-esteem score in the intervention group was significantly higher than the control group based on repeated measures ANOVA and with controlling the baseline score and variables of participants' and their spouses' educational level, participants' age, and intervals between their pregnancies (adjusted mean difference (AMD): 7.18; 95\%confidence interval (Cl): 4.43 to 9.94; $p<0.001$ ) (Table 3)

Table 3

The mean (SD) of self-esteem before, immediately after intervention \& 4 weeks after child birth.

\begin{tabular}{|c|c|c|c|c|}
\hline \multirow[t]{2}{*}{ Variable } & $\begin{array}{l}\text { Intervention group } \mathrm{n} \\
=33\end{array}$ & $\begin{array}{l}\text { Control group } n \\
=33\end{array}$ & $\operatorname{AMD}(95 \% \mathrm{Cl}) \ddagger$ & $\begin{array}{l}\mathrm{p}- \\
\text { value }\end{array}$ \\
\hline & Mean (SDt) & \multicolumn{3}{|l|}{ Mean (SD) } \\
\hline Before intervention & $15.63(3.18)$ & $17.82(3.39)$ & $\begin{array}{l}-2.20(-3.77 \text { to } \\
-0.63)\end{array}$ & 0.007 \\
\hline $\begin{array}{l}\text { Immediately after } \\
\text { intervention }\end{array}$ & $23.36(2.34)$ & $18.40(2.06)$ & $\begin{array}{l}7.18 \text { (4.43 to } \\
9.94)\end{array}$ & $<$. \\
\hline 4 weeks after childbirth & $24.36(2.50)$ & $17.13(3.40)$ & & \\
\hline \multicolumn{5}{|c|}{$\begin{array}{l}\text { The independent t-test was used for comparison of the groups before the intervention and repeated } \\
\text { measure ANOVA with controlling baseline score and variables of participants \& their spouse's } \\
\text { education level, participant's age and interval between deliveries was used for comparing them after } \\
\text { the intervention. }\end{array}$} \\
\hline \multicolumn{5}{|c|}{ The number of participants before intervention was 70 and after intervention was 66 . } \\
\hline \multicolumn{5}{|l|}{ †Standard Deviation } \\
\hline \multicolumn{5}{|c|}{$\ddagger$ Adjusted Mean Difference (95\% Confidence Interval) } \\
\hline
\end{tabular}

Mean (SD) of body image, before the intervention, was 214.48 (13.16) in the intervention group and 215.63 (14.10) in the control group. This score, immediately after the intervention, was 264.86 (15.97) in the intervention group and 214.66 (21.67) in the control group; and 4 weeks after childbirth, it was 270.07 (15.25) in the intervention group and 211.00 (17.48) in the control group. Before the intervention, there was no significant statistical difference between two groups based on independent t-test $(p=0.727)$. However, after the intervention, mean body image score in the intervention group was significantly higher than the control group based on repeated measures ANOVA with controlling the baseline score and variables like participants' and their spouses' educational level, participants' age, and intervals between their pregnancies (AMD: 49.74; $95 \% \mathrm{Cl}=28.57$ to $70.91 ; \mathrm{p}<0.001$ ) (Table 4). 
Table 4

The mean (SD) of body image and its subscales before, immediately after and 4 weeks after childbirth

variable
Intervention group $\mathbf{n}$ $=33$

Mean (SDt)
Control group $\mathrm{n}$ $=33$

Mean (SD)
$\mathrm{AMD} \ddagger(95 \% \mathrm{Cl})$

value

\section{Total body image}

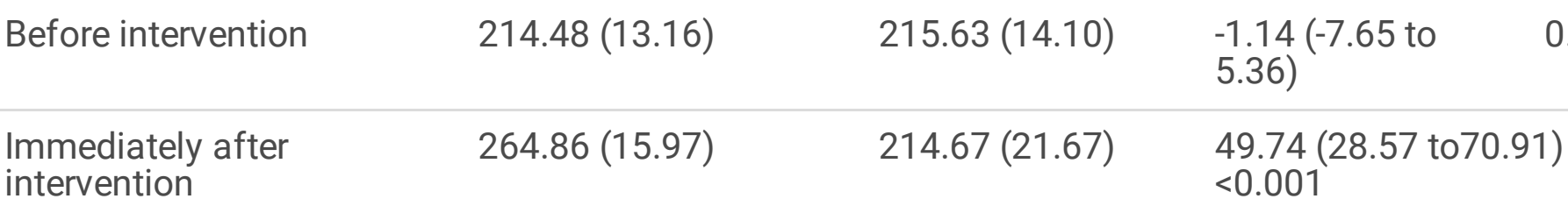

4 weeks after delivery

$270.07(15.25)$

$211.0(17.48)$

\section{Appearance evaluation}

Before intervention

$17.97(2.87)$

$19.80(4.30)$

-1.83 (3.57 to $-0.85)$

Immediately after

$27.28(4.60)$

$21.53(4.88)$

6.64 (1.80 to 11.48$) 0.010$

intervention

$28.14(4.90)$

$19.93(3.08)$

4weeks after delivery

$28.14(4.90)$

$19.93(3.08)$

\section{Appearance orientation}

Before intervention

$44.77(6.34)$

$42.43(5.15)$

$2.34(-0.41$ to

0.094

$5.10)$

Immediately after

intervention

$50.21(3.62)$

(6.44) 40.33

9.26 (4.71 to 13.82$) 0<$ 001

4 weeks after delivery

50 (4.62)

$41.66(5.42)$

\section{Fitness evaluation}

Before intervention

$7.60(1.63)$

$8.06(1.89)$

$-0.46(-1.30$ to

0.283

Immediately after

intervention

$$
11.14 \text { (2.38) }
$$

4 weeks after delivery

$11.57(2.47)$

(1.81) 7.53

3.30 (1.20 to 5.40$)$

\section{Fitness orientation}

The independent t-test was used for comparison of the groups before the intervention and repeated measure ANOVA with controlling baseline score and variables of participants and their spouse's education level, participant's age \& interval between deliveries was used for comparing them after the intervention.

The number of participants was 70 before the intervention and 66 after the intervention.

tstandard deviation łmean difference (confidence interval 95\%) 


\begin{tabular}{|c|c|c|c|c|}
\hline \multirow[t]{2}{*}{ variable } & $\begin{array}{l}\text { Intervention group } \mathrm{n} \\
=33\end{array}$ & $\begin{array}{l}\text { Control group } n \\
=33\end{array}$ & \multirow[t]{2}{*}{ AMD $\ddagger(95 \% \mathrm{Cl})$} & \multirow[t]{2}{*}{$\begin{array}{l}\mathrm{p} \text { - } \\
\text { value }\end{array}$} \\
\hline & Mean (SDt) & Mean (SD) & & \\
\hline Before intervention & $37.17(6.43)$ & $38.03(6.06)$ & $\begin{array}{l}-0.86(-3.84 \text { to } \\
2.12)\end{array}$ & 0.568 \\
\hline $\begin{array}{l}\text { Immediately after } \\
\text { intervention }\end{array}$ & (6.17) 47.71 & (6.63) 38.87 & \multirow{2}{*}{\multicolumn{2}{|c|}{$\begin{array}{l}10.96 \text { (5.06 to } 16.85) \\
0.001\end{array}$}} \\
\hline 4 weeks after delivery & (5.61) 49.28 & (5.42) 35.07 & & \\
\hline \multicolumn{5}{|l|}{ Health evaluation } \\
\hline Before intervention & $17.88(2.16)$ & $18.6(2.81)$ & $\begin{array}{l}-0.71(-1.91 \text { to } \\
0.48)\end{array}$ & 0.238 \\
\hline $\begin{array}{l}\text { Immediately after } \\
\text { intervention }\end{array}$ & $23.57(3.63)$ & $18.27(1.83)$ & \multirow{2}{*}{\multicolumn{2}{|c|}{5.73 (2.71 to 8.74 ) 0.001}} \\
\hline 4 weeks after delivery & (2.82) 23.86 & $18.07(2.63)$ & & \\
\hline \multicolumn{5}{|l|}{ Health orientation } \\
\hline Before intervention & $26.51(2.92)$ & $24.91(3.54)$ & $\begin{array}{l}1.60(0.05 \text { to } \\
3.15)\end{array}$ & 0.043 \\
\hline $\begin{array}{l}\text { Immediately after } \\
\text { intervention }\end{array}$ & $32.28(3.73)$ & $25.47(2.85)$ & \multirow[t]{2}{*}{$4.53(0.87$ to 8.19$)$} & 0.018 \\
\hline 4 weeks after delivery & (2.84) 32.93 & $25.87(3.77)$ & & \\
\hline \multicolumn{5}{|l|}{ Illness orientation } \\
\hline Before intervention & $18.71(2.89)$ & $18.31(2.63)$ & $\begin{array}{l}0.40(-0.92 \text { to } \\
1.72)\end{array}$ & 0.547 \\
\hline $\begin{array}{l}\text { Immediately after } \\
\text { intervention }\end{array}$ & $20.71(2.64)$ & $17.47(3.70)$ & \multirow[t]{2}{*}{4.37 (1.81 to 6.92$)$} & \multirow[t]{2}{*}{0.002} \\
\hline 4 weeks after delivery & $21.36(2.24)$ & $18.13(2.47)$ & & \\
\hline \multicolumn{5}{|l|}{ Pre BASS } \\
\hline Before intervention & $25.23(4.43)$ & $26.71(4.41)$ & $\begin{array}{l}-1.48(-3.60 \text { to } \\
0.62)\end{array}$ & 0.165 \\
\hline
\end{tabular}

The independent t-test was used for comparison of the groups before the intervention and repeated measure ANOVA with controlling baseline score and variables of participants and their spouse's education level, participant's age \& interval between deliveries was used for comparing them after the intervention.

The number of participants was 70 before the intervention and 66 after the intervention.

tstandard deviation łmean difference (confidence interval 95\%) 


\begin{tabular}{|c|c|c|c|c|}
\hline \multirow[t]{2}{*}{ variable } & $\begin{array}{l}\text { Intervention group n } \\
=33\end{array}$ & $\begin{array}{l}\text { Control group n } \\
=33\end{array}$ & \multirow[t]{2}{*}{ AMD $¥(95 \% \mathrm{Cl})$} & \multirow[t]{2}{*}{$\begin{array}{l}\mathrm{p}- \\
\text { value }\end{array}$} \\
\hline & Mean (SDt) & Mean (SD) & & \\
\hline $\begin{array}{l}\text { Immediately after } \\
\text { intervention }\end{array}$ & $34.43(5.62)$ & $27.67(6.18)$ & \multirow{2}{*}{\multicolumn{2}{|c|}{$5.74(-0.44$ to 11.92$) 0.067$}} \\
\hline 4 weeks after delivery & $35.36(5.34)$ & $27.53(5.19)$ & & \\
\hline \multicolumn{5}{|l|}{ Self-classified weight } \\
\hline Before intervention & $2.68(0.98)$ & $3.08(1.02)$ & $\begin{array}{l}-0.40(-0.88 \text { to } \\
0.08)\end{array}$ & 0.098 \\
\hline $\begin{array}{l}\text { Immediately after } \\
\text { intervention }\end{array}$ & $2.68(0.46)$ & $2.9(0.85)$ & \multirow[t]{2}{*}{$-0.15(-0.75$ to 0.45$)$} & \multirow[t]{2}{*}{0.594} \\
\hline 4 weeks after delivery & $1.34(0.23)$ & $1.40(0.48)$ & & \\
\hline \multicolumn{5}{|c|}{ Overweight preoccupation } \\
\hline Before intervention & $0.73(0.10)$ & $0.70(0.12)$ & $\begin{array}{l}0.03(-0.02 \text { to } \\
0.08)\end{array}$ & 0.217 \\
\hline $\begin{array}{l}\text { Immediately after } \\
\text { intervention }\end{array}$ & $2.82(0.61)$ & $2.57(0.47)$ & \multirow[t]{2}{*}{$-0.18(-0.77$ to 0.40$)$} & 0.524 \\
\hline 4 weeks after delivery & $2.82(0.51)$ & $2.65(0.54)$ & & \\
\hline \multicolumn{5}{|c|}{$\begin{array}{l}\text { The independent t-test was used for comparison of the groups before the intervention and repeated } \\
\text { measure ANOVA with controlling baseline score and variables of participants and their spouse's } \\
\text { education level, participant's age \& interval between deliveries was used for comparing them after the } \\
\text { intervention. }\end{array}$} \\
\hline \multicolumn{5}{|c|}{ The number of participants was 70 before the intervention and 66 after the intervention. } \\
\hline †standard deviation $\neq \mathrm{m}$ & difference (confidence & rval 95\%) & & \\
\hline
\end{tabular}

Body image has 10 subscales among which mean score of subscales of appearance evaluation $(p=$ $0.010)$, appearance orientation ( $p<0.001)$, fitness evaluation $(p=0.004)$, fitness orientation $(p=0.001)$, health evaluation $(p=0.001)$, health orientation $(p=0.018)$, illness orientation $(p=0.002)$ were significantly higher in the intervention group than the control group after intervention (Table 4)

$63.6 \%$ of mothers in the intervention group and $30.3 \%$ of mothers in the control group had exclusive breastfeeding that based on Chi-square test, was significantly higher in the intervention group than the control group $(p=0.007)$.

\section{Discussion}


The results of the present study confirmed the effectiveness of CBT on the improvement of self-esteem and body image among breastfeeding women and as a result the increase of the frequency of exclusive breastfeeding among women in the intervention group. Due to lack of articles evaluating desired variables in breastfeeding women, articles that evaluated the effectiveness of CBT on self-esteem and body image in other population groups were compared.

In the present study, cognitive-behavior counseling led to self-esteem improvement in intervention group women. In a study conducted by Vakilian et al. (2018) [28] evaluating the effectiveness of cognitivebehavior counseling on self-esteem of primiparous pregnant women, the effectiveness of CBT on improving self-esteem score was confirmed. The results of a study conducted by Farahzadi et al. (2019) [34] to analyze the effects of CBT on self-esteem of women suffering from body image dissatisfaction showed that self-esteem improved significantly in the intervention group. The results of Babadi's (2019) [35] study on obese women with $\mathrm{BMI}>30$ also indicated the effectiveness of CBT on self-esteem. However, in Myung-Sun Hyun's (2005) [44] study, self-esteem was not improved significantly in the group receiving $C B T$. The different research population of this study might be considered as one of the causes of this difference; Myung-sun Hyun's study was done on adolescent boys. By changing maladaptive thoughts and correcting fundamental misconceptions, CBT can bring about emotional and behavioral changes and through which can improve self-esteem [45].

In the present study, cognitive-behavior counseling led to body image improvement in intervention group women. Likewise, in a study conducted by Navidian et al. (2016) [46] on women 20-40 years old 3 months after their delivery, CBT led to body image improvement in the intervention group compared to the control group. In a study, Ahmadi et al. (2017) [47] analyzed the effects of CBT on infertile women's body image and concluded CBT improved body image. In Ahmadi's study, like the present study, CBT improved subscales of appearance evaluation, appearance orientation and fitness evaluation. Moreover, in his study, like the present study, there was no significant difference regarding self-classified weight between two groups after the intervention. Appearance evaluation is a subscale selected internationally for assessment of appearance concerns. This subscale evaluates the subject's feelings concerning appearance attractiveness and her satisfaction with her appearance. The subscale appearance orientation investigates biases and attitudes related to appearance [48]. The subscale fitness evaluation also relates to general assessment of body fitness, and self-classified weight analyzes the subject's concerns about his/her weight [46]. In a study by Fadaei et al. (2011) [50] CBT was also effective on body image improvement of women after mastectomy. Cognitive-behavior therapy changes maladaptive thoughts by combining cognitive and behavioral approaches, and as a result, leads to a comprehensive understanding of body image and the factors related to it [51].

In the present study, the frequency of exclusive breastfeeding in the intervention group was significantly higher than the control group. In Navidian's [46] study, breastfeeding rate was analyzed too and no significant difference between two groups was found and it was different from the results of the present study. Cultural differences and different socio-economic levels of study populations of two studies are the probable causes of this difference. Navidian's study was conducted in one of the socio-economic 
deprived provinces. Also, in our study counseling sessions started in pregnancy and continued for 8 sessions; besides, Navidian's study was conducted just among primiparous women who had no previous history of breastfeeding, while our study included women with a second delivery as well as primiparous women too. In Sikander's (2015) [45] study, similar to our study, cognitive-behavior approach increased the frequency and length of exclusive breastfeeding, $59.6 \%$ of women in the intervention group had exclusive breastfeeding while the percentage was $28.6 \%$ in the control group. The results of Rahman's (2012) [52] study also show the effectiveness of cognitive-behavior approach on exclusive breastfeeding. Psychotherapy approaches bring about cognitive environment necessary for behavior change [53]. Among them, CBT provides mothers with the opportunity to apply knowledge in practice by presenting assignments and practices, so leads to long-term behavior change in mothers [54] and through which improvement of health behaviors in them.

Following up participants for one month after delivery was one of the strength points of this study. Using standard questionnaires was one of other strength points of this study. One of the limitations of the present study was the low number of participants in counseling groups because of pandemic Coronavirus. Also, women with high-risk pregnancies or with depression history were excluded from the study; thus, it is suggested to investigate the effects of CBT on women with high-risk pregnancies in the future studies.

\section{Conclusions}

Counseling using cognitive-behavior approach improved self-esteem and body image in breastfeeding women and, as a result of it, frequency of exclusive breastfeeding also increased in the group that received counseling. Thus, it is suggested to provide women with access to self-esteem and body image counseling during pregnancy period; and since midwifery consultants are competent in different approaches of psychology as well as midwifery knowledge, their presence besides mothers during the sensitive periods of pregnancy and breastfeeding can help mothers and health system greatly.

\section{Abbreviations}

CBT: cognitive behavior therapy; MBSRQ: multidimensional body self-relation questionnaire; AMD: adjusted mean difference; SD: standard deviation; BMI: body mass index; B.F: breastfeeding

\section{Declarations}

\section{Acknowledgments}

We sincerely appreciate all of the women participated in this study and all of the health centers that cooperated with us perfectly.

\section{Financial support}


This study was performed with the support of Tabriz University of Medical Sciences. The investor had no role in designing the study, collecting data, and data analysis ....

\section{Authors' contributions}

N.Z, M.K and M.M conceived and designed the study. F.N designed the CBT protocol. N.Z conducted the therapy protocol and the study. M.K and M.M critically revised the manuscript. All authors have read and approved the final manuscript.

\section{Ethics approval and consent to participate}

This study is extracted from a master's thesis that registered at IRCT (code: IRCT20110524006582N33) and has been approved by the ethics committee of Tabriz university of medical sciences, Iran. Ethics code: IR.TBZMED.REC.1398.10.99. Written informed consent was obtained from all participants.

\section{Consent for publication}

Not applicable

\section{Competing interests}

No conflict of interest

\section{References}

1. 'Self-esteem.'Merriam-Webester.com,Dictionary,Merriam -Webester, available from: https://www.merriam-webster.com/dictionary/self-esteem, access date 1 feb,2021.

2. Garcìa JA, y Olmos FC, Matheu ML,Carreño T.P. Self esteem levels vs global scores on the Rosenberg self-esteem scale. Heliyon.2019;5(3):e01378. Doi: 10.1016/j.heliyon.2019.e01378 .

3. Rosenberg, M. Conceiving the self: Malabar (fla):Robert E. Krieger.Rosenmann, A and Safir , M.P. (2006). Forced online: push factors of interrnet sexuality: A preliminary study of online paraphilic empowerment journal of Homosexuality. 1986;51(3):71-92

4. Zhang L, Yu Q, Zhang Q, Yafei G, Jianwen Ch. The relationship between explicit self-esteem and subjective well-being: The moderating effect of implicit self-esteem. The Journal of general psychology. 2020; 147(1):1-17. https://doi.org/10.1080/00221309.2019.1609896 .

5. Harris MA, Orth U. The link between self-esteem and social relationships: A meta-analysis of longitudinal studies. Journal of personality and social psychology. 2020;119(6):1459.

6. Zeigler-Hill V. The importance of self-esteem. In V. Zeigler-Hill (Ed.), current issues in social psychology. Self-esteem (p.1-20). 2013.https://doi.org/10.4324/9780203587874 .

7. Orth, U.\& Robins ,R.W. Development of self-esteem across the lifespan. In D.P. McAdams, R. L. Shiner, \& J. L. Tackett (Eds.), Handbook of personality develpoment New York, NY: Guilford. 2019. (pp.328344). 
8. Sowislo JF, Orth U. Does low self-esteem predict depression and anxiety? A meta-analysis of longitudinal studies. Psychological bulletin. 2013 jan;139(1)213-240.PMID: 22730921; doi: 10.1037/a0028931.

9. Santos PC, Abreu s, Moreira C, Santos R, Ferreira M, Alves O.et al. Physical activity patterns during pregnancy in a sample of portuguese women: A longitudinal Prospective Study. Iran Red Crescent Med J.2016 Mar 28;18(3):e22455.doi: 10.5812/ircmj.22455.PMID:27247788 .

10. Bödecs T, Horváth B, Szilágyi E, Gonda X, Rihmer Z, Sándor J. Effects of depression, anxiety, selfesteem, and health behaviour on neonatal outcomes in a population-based Hungarian sample. European Journal of Obstetrics \& Gynecology and Reproductive Biology. 2011;154(1):45-50. https://doi.org/10.1016/j.ejogrb.2010.08.021.

11. Maçola L, do Vale IN, Carmona EV. Assessment of self-esteem in pregnant women using Rosenberg's Self-Esteem Scale. Rev.Esc.Enferm. USP.2010 Sep.1;44(3):570-7.Available from: https://www.revistas.usp.br/reeusp/article/view/40578.

12. Kendra Cherry.what is self-esteem?,very well mind. updated on March 2021. Available from: https://www.verywellmind.com/what-is-self-esteem-2795868.

13. Chang HJ, Suttikun C. The examination of psychological factors and social norms affecting body satisfaction and self-esteem for college students. Family and consumer sciences research Journal. 2017; 45(4):422-37. https://doi.org/10.1111/fcsr.12220.

14. Kamalifard M, Mirghafourvand M, Ranjbar F, et al. relationship of Breastfeeding Self-Efficacy with Self-Esteem and General Health in Breastfeeding Mothers Referred to Health Centers of Falavarjan City-Iran,2015. Community Mental Health journal. 2019 Aug;55(6):1057-1063. https://doi.org/10.1007/s10597-019-00408-6.

15. Gow ML, Tee MS, Garnett SP, Baur LA, Aldwell K, Thomas S et al. Pediatric obesity treatment, selfesteem, and body image: A systematic review with meta-analysis. Pediatric obesity. 2020;15(3):e12600.

16. NEDA,body image: national eating disorder collabration; 2021 [cited 2021]. Available from: https://www.nationaleatingdisorders.org/body-image-0.

17. NEDC N. Body Image 2020. Available from: https://nedc.com.au/eating-disorders/eating-disordersexplained/body-image/.

18. Shoraka H, Amirkafi A, Garrusi B. Review of body image and some of contributing factors in Iranian population. International journal of preventive medicine. 2019;10. https://doi.org/10.4103/20087802.252143 .

19. Rahmanian V, Zolala F, Mohseni M, Baneshi M, Khalili N. Relationship between body image and social participation in pregnant women of Jahrom city, Iran. The Horizon of Medical Sciences. 2017;23(2):111-6. https://doi.org/10.18869/acadpub.hms.23.2.111.

20. Boscaglia N, Skouteris H, Wertheim EH. Changes in body image satisfaction during pregnancy: A comparison of high exercising and low exercising women. Australian and New Zealand Journal of Obstetrics and Gynaecology. 2003;43(1):41-5. https://doi.org/10.1046/j.0004-8666.2003.00016.x. 
21. Williams K. The relationship between body image and mother to infant attachment in the postpartum period:D.Clin.Psychol thesis, University of Leeds; 2019.

22. Rasool Heshmati, Khodaparast S, Fatemeh Koroghipoor. The predictive role of body image, body mass index, dispositional mindfulness and alexithymia in marital satisfaction of employed women. Journal of Women Social and Psychological Studies. 2017;14(4):43-68.

23. Paans NP, Bot M, Brouwer IA, Visser M, Pennix BW. Contributions of depression and body mass index to body image. Journal of psychiatric research. 2018;103:18-25. http://dx. doi.org/10.1016/j.jpsychires.2018.05.003.

24. Murnen SK, Smolak L. The Cash effect: Shaping the research conversation on body image and eating disorders. Body image. 2019;31:288-93.

25. Garrusi B, Razavi Nematallahee V, Etminan A. The relationship of body image with depression and self-esteem in pregnant women. Health and Development Journal. 2013;2(2):117-27. DOI: 10.4103/ijnmr.IJNMR_178_16.

26. Chan CY, Lee AM, Koh YW, Lam SK, Lee CP, Leung Ky, et al. Associations of body dissatisfaction with anxiety and depression in the pregnancy and postpartum periods: A longitudinal study. Journal of affective disorders. 2020;263:582-92. DOI: 10.1016/j.jad.2019.11.032.

27. Morley-Hewitt AG, Owen AL. A systematic review examining the association between female body image and the intention, initiation and duration of post-partum infant feeding methods (breastfeeding vs bottle-feeding). Journal of health psychology. 2020;25(2):207-26. https://doi.org/10.1177/1359105319833744.

28. Vakilian K, Poorjandaghi M, Khorsandi M. Effectiveness of cognitive group counseling to self-esteem in nulliparous women. Journal of Clinical Nursing and Midwifery. 2018;4(3)::67-74.

29. Mäkikangas A, Kinnunen U, Feldt T. Self-esteem, dispositional optimism, and health: Evidence from cross-lagged data on employees. Journal of research in personality. 2004;38(6):556-75.

30. Brown TA, Cash TF, Mikulka PJ. Attitudinal body-image assessment: Factor analysis of the Body-Self Relations Questionnaire. Journal of personality assessment. 1990;55(1-2):135-44.

31. Cash TF. The multidimensional body-self relations questionnaire. Unpublished test manual, Old Dominion University, Norfolk, VA. 1990.

32. Rahati A. Evolutionary study of body image and its relationship with self-esteem based on comparison between adolescent, middle age and old people. Tehran: Shahed University. 2004;34.

33. Barez A, Maleki N. Self Esteem and its Associated Factors in Primiparous mothers Referred to health centers in the city of Mashhad. Journal of Clinical Nursing and Midwifery. 2016;519:(2)-28.

34. Farahzadi M, Maddahi ME, Khalatbari J. Comparison The effectiveness Acceptance and Commitment group therapy and Cognitive-Behavior group therapy on Perfectionism and self-esteem women with body image dissatisfaction. Clinical Psychology \& Personality (Daneshvar Raftar). 2019;17(1 (32)):97-108.

35. Babadi A, Kajbaf MB, Nouri A, Abedi MR. The impact of lived-experience based therapy and cognitivebehavior therapy on body mass index and self-esteem among obese women. International Journal of 
Applied Behavioral Sciences. 2019;6(3):52-60. https://doi.org/10.22037/ijabs.v6i3.27751.

36. Ekrami F, Mirghafourvand M, Farzipour SH. Comparison of the Body Image Between Women Seeking Female Genital Cosmetic Surgery and Women Not Interested in FGCS: A Case Control Study. Crescent Journal of Medical and Biological Sciences. 2018;5. 337-332:(4)

37. Xu ML, Leung SO. Effects of varying numbers of Likert scale points on factor structure of the Rosenberg Self-Esteem Scale. Asian Journal of Social Psychology. 2018;21(3):119-28.

38. Supple AJ, Su J, Plunkett SW, Peterson GW, Bush KR. Factor structure of the Rosenberg self-esteem scale. Journal of Cross-Cultural Psychology.2013 Jul;44(5):748-

64. https://doi.org/10.1177/0022022112468942.

39. Barkhordary M, Jalalmanesh S, Mahmodi M. The relationship between critical thinking disposition and self esteem in third and forth year bachelor nursing students. Iranian journal of medical education. 2009;9(1):13-19.

40. Strachan MD, Cash TF. Self-help for a negative body image: A comparison of components of a cognitive-behavioral program. Behavior Therapy. 2002;33(2):235-251.

41. Free ML, Elliott, Charles H. cognitive therapy in groups: guide lines and resources for practice,Journal of cognitive psychotherapy.2014;15(2). https://doi.org/10.1891/0889-8391.15.2.147.

42. Rajabi G, Karjo KS. A study of confirmatory structure two-factor model of the Persian version Rosenberg self-esteem scale, Journal of Psychological models and methods. 2012;2(6):33-43.

43. Inanir S, Cakmak B, Nacar MC, Culer A, Inanir A. Body Image perception and self-esteem during pregnancy. Journal of womens health and reproduction sciences,201;3(4),196-200.

44. Hyun M-S, Chung H-IC, Lee Y-J. The effect of cognitive-behavioral group therapy on the self-esteem, depression, and self-efficacy of runaway adolescents in a shelter in South Korea. Applied Nursing Research. 2005;18(3):160-166. .DOI: 10.1016/j.apnr.2004.07.006.

45. Sikander S, Maselko J, Zafar S, Haq Z, Ahmad L, Ahmad M, et al. Cognitive-behavioral counseling for exclusive breastfeeding in rural pediatrics: a cluster RCT. Pediatrics. 2015;135(2):e424-e31. Doi:10.1542/peds.2014-1628.

46. Navidian A, Moudi Z, Esmaealzade M. The Effectiveness of Group Cognitive Behavioral Therapy Based on Cash's Eight-Step Model in Body Image of Primiparous Women. Iranian Journal of Psychiatry and Behavioral Sciences. 2017;11(2);7236.

47. Ahmadi Z, Abbaspoor Z, Behroozy N, et al. The effects of cognitive behavioral therapy on body image in infertile women. Iranian Red Crescent Medical Journal. 2017;19(10):0-0.

48. King TK, Matacin M, Marcus BH, Bock BC, Tripolone J. Body image evaluations in women smokers. Addictive Behaviors. 2000;25(4):613-618. https://doi.org/10.1016/S0306-4603(99)00039-8.

49. Annis NM, Cash TF, Hrabosky JI. Body image and psychosocial differences among stable average weight, currently overweight, and formerly overweight women: the role of stigmatizing experiences. Body image. 2004;1(2):155-167. DOI:10.1016/j.bodyim.2003.12.001. 
50. Fadaei S, Janighorban M, Mehrabi T, et al. Effects of cognitive behavioral counseling on body Image following mastectomy. Journal of research in medical sciences: the official journal of Isfahan University of Medical Sciences. 2011;16(8):1047-1054.

51. Hofmann SG, Asnaani A, Vonk IJ, Sawyer AT, Fang A. The efficacy of cognitive behavior therapy:A review of meta-analyses. Cognitive therapy and research. 36(5),427-440.doi: 10.1007/s10608-0129476-1.

52. Rahman A, Haq Z, Sikander S, Ahmad L. Using cognitive-behavioural techniques to improve exclusive breastfeeding in a low-literacy disadvantaged population. Maternal \& child nutrition. 2011;8(1):57-71. DOI:10.1111/j.1740-8709.2011.00362.x .

53. Rahman A, Malik A, Sikander S, Roberts C. Cognitive behaviour therapy-based intervention by community health workers for mothers with depression and their infants in rural Pakistan: a clusterrandomised controlled trial. The Lancet. 2008;372(9642):902-909.Doi:10.1016/S01406736(08)61400-2.

\section{Figures}




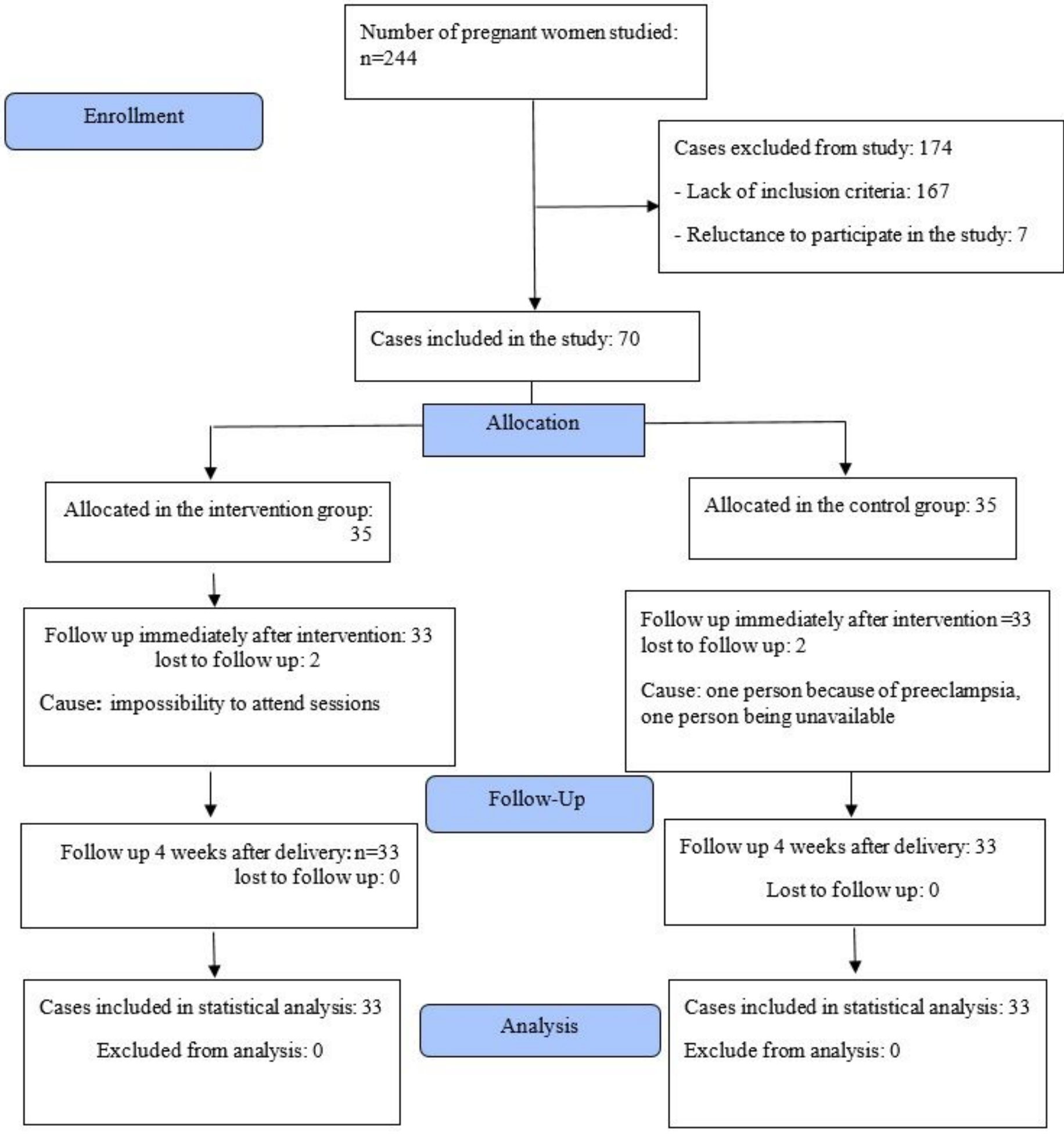

\section{Figure 1}

The study follow chart 